\title{
Fatigue life assessment regarding different influences on the HCF/VHCF behavior of a martensitic steel
}

\author{
Igor Milošević ${ }^{1,}$, Benjamin Seisenbacher ${ }^{1}$, Gerhard Winter $^{1}$, Florian $_{\text {Grün }}{ }^{1}$, Martin Kober $^{2}$ \\ ${ }^{1}$ Chair of Mechanical Engineering, Montanuniversität Leoben, Franz-Josef-Strasse 18, Leoben 8700, Austria \\ ${ }^{2}$ LEC GmbH, Inffeldgasse 19/II, Graz 8010, Austria
}

\begin{abstract}
Modern applications require a special treatment when the conventional specimen size is much larger than the component size. Additional to that, high sophisticated materials are used for highly loaded components. Often the conventional fatigue limit is exceeded and loads are applied in the VHCF regime. Focus was put on the lifetime calculation and the implementation of investigated fatigue data of a $\mathrm{X} 5 \mathrm{CrNiCuNb}-16-4$ type steel. Two specimen geometries with diameters $\mathrm{D}_{7.5}=7.5 \mathrm{~mm}$ and $\mathrm{D}_{2.5}=2.5 \mathrm{~mm}$ were tested at $\mathrm{R}=-1$, at room temperature and up to $10^{9}$ cycles to failure. The application of different software tools (FEMFAT, fe-safe) showed several issues based on the current results. Results showed a change of crack initiation mechanism to subsurface crack initiation at approx. $2 \times 10^{6}$ cycles to failure. The gradient based correction of the reference fatigue data showed a good applicability up to $2 \times 10^{6}$ cylces. The application of fe-safe allows the flexible modification of $\mathrm{S} / \mathrm{N}$ parameters over the whole cycle range. The usage of the actual material configuration introduced several important questions regarding the fatigue data and the implementation into lifetime calculation tools.
\end{abstract}

\section{Introduction}

Nowadays modern applications require a number of superior characteristics (strength, ductility, etc.) served by high sophisticated structural materials. Precipitation hardened (PH) steels (Maraging) are well known as structural materials for chemical and power plants or as components in the aerospace and automotive industry.

Since the conventional fatigue limit has been questioned by numerous scientists, Bathias [1,2], Murakami [3,4] Mughrabi [5,6] and Miller [7] amongst others, so-called fish eye fractures introduced a new level of complexitiy to a long life fatigue behaviour. The change to an inclusion driven failure mechanism is accompanied by an increase of scatter and no infinite life.

Especially PH steels show a clear defect based life behaviour at longer lifetimes. [8] Several contributions were made from Schnitzer [9-11], Wang [12,13,13,14], $\mathrm{Wu}[14,15]$ and Schönbauer [16] concerning the microstructural and mechanical properties, study on temperature effects and the fatigue limit prediction by defect based models. It can be summarised that certain materials (type II, definition after [17]) with brittle inclusions (oxides) show a pronounced change of fatigue behaviour by inclusion based crack initiation.

In the process of fatigue life assessments fatigue data is used and implemented into common software tools (FEMFAT, fe-safe). These tools were not intended to cover changing failure mechanisms and different failure effects. Therefore a strategy has to be developed how to apply these tools up to the component based life assessment.

In most applications (lifetime estimation) the specimen geometry is usually smaller than the component size. In an actual case, the component size is much smaller than the specimen geometry.

In this work, fatigue results are shown regarding different influences and the application for a lifetime estimation process. Two software tools are compared presenting the pros and cons. Possibilities to cover certain influences are pointed out, and an outlook is given. The most important insights are concluded at the end.

\section{Experimental procedures}

\subsection{Material}

Fatigue experiments are performed with precipitation hardened stainless steel (X5CrNiCuNb164). The material specification is given in Table 1 below. The same material configuration was used in previous fatigue tests $[8,18]$.

Table 1. Chemical composition (max. value) of selected chemical elements of a X5CrNiCuNb-16-4 steel (wt\%, DIN EN 10088-3)

\begin{tabular}{lcccc}
\hline & $\mathrm{C}$ & $\mathrm{Cr}$ & $\mathrm{Mo}$ & $\mathrm{Ni}$ \\
\hline $\mathrm{X} 5 \mathrm{CrNiCuNb16}$ & 0.07 & 17.0 & 0.6 & 5.0 \\
\hline
\end{tabular}

Corresponding author: igor.milosevic@unileoben.ac.at 
The heat treatment of the material is austenitizing at approx. $1050{ }^{\circ} \mathrm{C}$ followed by a specific heat treatment, which induced intermetallic precipitations throughout the material matrix. Depending on the purpose (maritime applications, aerospace applications, etc.) a UTS of $1400 \mathrm{MPa}$ can be reached besides an excellent corrosion behaviour.

The microstructure is characterised by a fine lath martensitic structure $(<1 \mu \mathrm{m})$ without any significant (detectable) reverted austenite. The precipitation hardening increased strength and hardness.

\subsection{Fatigue testing method}

Fatigue tests in this work were conducted with two different testing machines. Common servo-hydraulic test rig (30 Hz testing frequency) as well as an own developed high frequency vibration technique (HVFT [19], $30 \mathrm{~Hz}, 928 \pm 8 \mathrm{~Hz}$ testing frequency) were used.

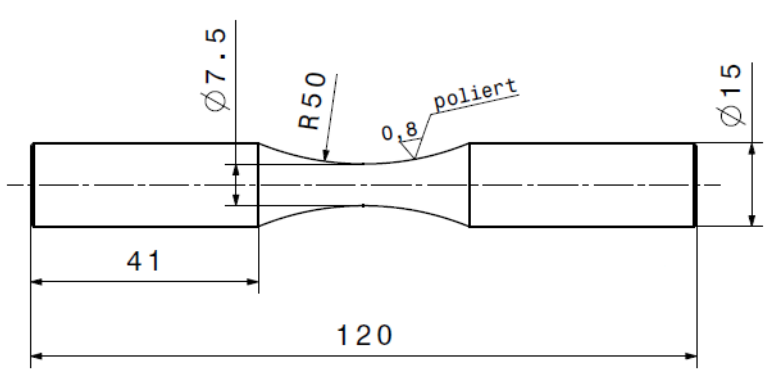

Fig. 1. Shape of standard hourglass $\left(D_{7.5}=7.5 \mathrm{~mm}\right)$ specimens. The critical cross section was diamond polished to its final condition.

In Fig. 1 and Fig. 2 the specimen shapes are pointed out, which were used in presented investigations. HFVT specimens were also used and validated within a recent work [19]. All specimens were diamond polished in the critical cross section.

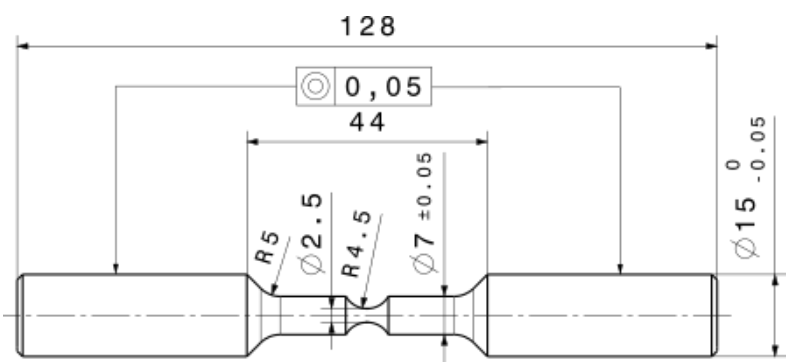

Fig. 2. Shape of a HFVT specimen $(D=2.5 \mathrm{~mm})$. The critical cross section was diamond polished to its final condition. [19]

Standard $30 \mathrm{~Hz}$ tests were carried out on the servohydraulic test rig Sinus 100.25 (Instron $\mathrm{GmbH}$, $\pm 100 \mathrm{kN})$ and high frequency tests ( $928 \pm 8 \mathrm{~Hz}, \mathrm{R}=-1$, $\mathrm{T}=25^{\circ} \mathrm{C}$ ) on the HFVT, which can be seen in Fig. 3.

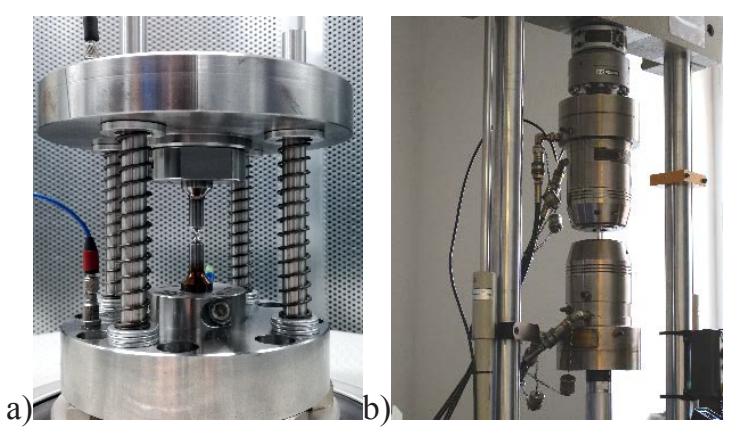

Fig. 3. Different fatigue test systems a) HFVT [19] and b) Sinus 100.25 (Instron $\mathrm{GmbH}, \pm 100 \mathrm{kN}$ )

\subsection{Fractography}

Representative fracture surfaces were analysed by SEM (EVO MA15, Carl Zeiss SMT). Due to the presence of a transition area (TA, [8]), where internal crack initiation was detected, EDS (Energy Dispersive $\mathrm{X}$-Ray Spectroscopy) was used to determine the type of inclusion. No further defect-based investigations were carried out in this work.

\section{Stress and life computation}

Modern software tools are implemented in product development cycles, which mostly combine a finite element analysis (FEA, Abaqus/CAE) with certain post processing tools, such as FEMFAT or fe-safe. Due to a wide availability the presented study focuses on uniaxial damage models. This preliminary work is seen as an initial step for further component based implementations.

The FEA was carried out by a detailed stress analysis of presented geometries (Fig. 1, Fig. 2). Therefore twenty-node brick elements, C3D20, were used (quadratic order). Reduced integration was

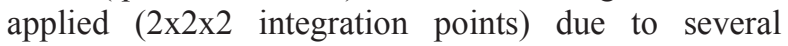
preliminary analyses published in [20,21].

Both specimens were loaded with a uniaxial nominal stress of $1 \mathrm{MPa}$. Material parameters (Table 2.) were given in the table below. No plastic deformation was applied.

Table 2. Material parameters $\mathrm{E}$ and $v$ used for stress calculations

\begin{tabular}{lcc}
\hline & E in GPa & $v$ \\
\hline Steel & 210 & 0.3 \\
\hline
\end{tabular}

The life computation was carried out by application of commonly known software tools FEMFAT and fesafe.

The evaluation of local stress conditions, like the application of the relative stress gradient $\chi$, lead to a modification of a referenced fatigue behaviour respectively $\mathrm{S} / \mathrm{N}$ curve. Equation 1 briefly describes the calculation of $n_{\chi}$ where the tension/ compression fatigue limit $\sigma_{\mathrm{t}}$, the rotating bending fatigue limit $\sigma_{\mathrm{rb}}$, the relative stress gradient $\chi$ ' and a material parameter $\mathrm{K}_{\mathrm{D}}$ were implemented. A detailed description of this 
application is given by Eichlseder [22] and in recent studies by the authors [20,21].

$$
\mathrm{n}_{\chi}=1+\left(\frac{\sigma_{\mathrm{rb}}}{\sigma_{\mathrm{t}}}-1\right) *\left(\frac{\chi^{\prime}}{2 / \mathrm{b}}\right)^{\mathrm{K}_{\mathrm{D}}}
$$

The local fatigue limit $\sigma_{\mathrm{f}}$ is calculated by Equation 2. Within the adjustment of the fatigue limit also the slope $\mathrm{k}$ and the cycles to the turn off point $\mathrm{N}_{\mathrm{D}}$ are modified. This procedure was implemented by FEMFAT and therefore no additional description will be given.

$$
\sigma_{\mathrm{f}}=\sigma_{\mathrm{t}} * \mathrm{n}_{\chi}
$$

Several procedures are suggested for damage calculations at stress amplitudes below the fatigue limit. The three most important approaches are Miner Modified, Miner Original and Miner Elementary. Miner Original assumes that a pronounced fatigue limit is present whereas Miner Elementary treats all stress amplitudes equally. Miner Modified proposes a second slope according to $\mathrm{k}_{2}=2 * \mathrm{k}_{1}-1$.

The software tool fe-safe (developed by Dassault Systemes) is capable of lifetime calculations by different approaches. A major difference is obvious by implementation of $\mathrm{S} / \mathrm{N}$ curves. Whereas FEMFAT uses parameters $\mathrm{k}, \mathrm{N}_{\mathrm{D}}$ and $\sigma_{\mathrm{t}}$, fe-safe directly implements $\mathrm{S} / \mathrm{N}$ datapoints. These datasets are connected and where no data is found an extrapolation is carried out. An according algorithm was chosen for lifetime calculations. Among others v. Mises, Normal Stress, etc. criteria are available with additional possibility of mean stress corrections.

A stress concentration based approach was not implemented. A major advantage is the variable implementation of $\mathrm{S} / \mathrm{N}$ datapoints. Therefore a double kinked $\mathrm{S} / \mathrm{N}$ curve, for example, allowed a more sophisticated application in the VHCF area.

\section{Results}

\subsection{Fatigue and fractrography}

In this section results are discussed with respect to specimen diameters $\mathrm{D}_{7.5}$ and $\mathrm{D}_{2.5}$. Fatigue tests were stopped at $10^{7}$ cycles, unless otherwise stated, and specimens were categorised as run out tests.

$\mathrm{S} / \mathrm{N}$ (Wöhler) curves displayed were generated by statistical evaluation of fatigue tests according to ASTM E739 [23] and $\arcsin \sqrt{\mathrm{P}}$ [24] representing a survival propability of $\mathrm{P}_{\mathrm{S}}=50 \%$.

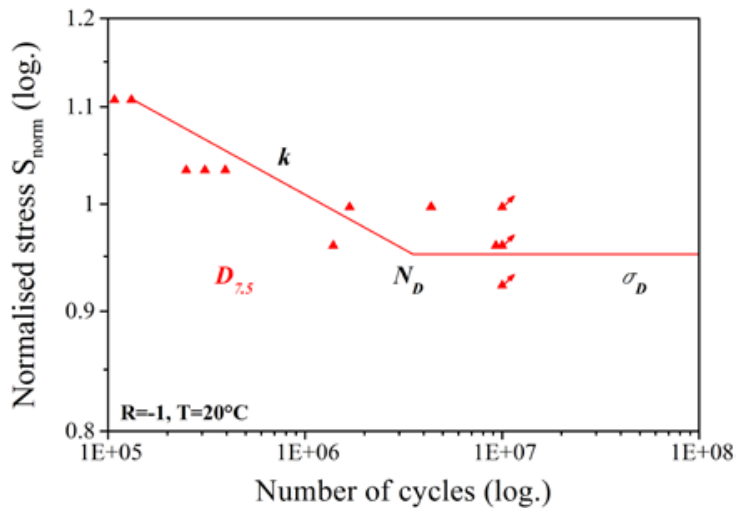

Fig. 4. Fatigue data from $D_{7.5}$ specimen geometries. $D_{7.5}$ specimens were tested at $30 \mathrm{~Hz}, \mathrm{R}=-1$ and at roomtemperature.

$\mathrm{D}_{7.5}$ fatigue results were considered as reference fatigue tests. As pointed out in Fig. 4 tests were conducted at $\mathrm{T}=20^{\circ} \mathrm{C}$ and at a stress ratio $\mathrm{R}=-1$. Parameters $\mathrm{k}=21.5, \mathrm{~N}_{\mathrm{D}}=3,287,500$ at a $\mathrm{S}_{\text {norm }}=0.95$ were derived from statistical evaluations and implemented in FEMFAT.

Additional tests $\mathrm{D}_{2.5}$ were conducted at $928 \pm 8 \mathrm{~Hz}$, which were stopped after $10^{9}$ cycles without failure. In the area up to $2 \times 10^{6}$ cycles to failure the slope increased due to the geometrical specimen properties. As expected a higher overall fatigue strength was observed in comparison with $30 \mathrm{~Hz}$ results. Up to $2 \times 10^{6}$ cycles to failure crack initiation mainly took place on the specimen surface.

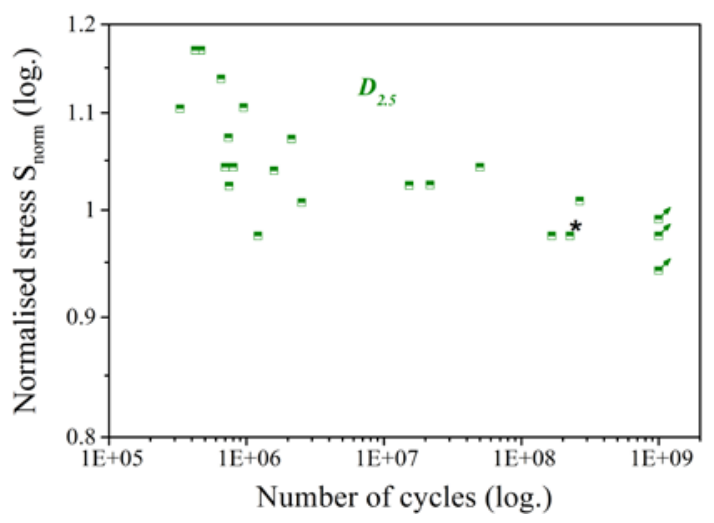

Fig. 5. Fatigue data from $D_{2.5}$ specimen geometries. Tests were conducted at $928 \pm 8 \mathrm{~Hz}, \mathrm{R}=-1$. [19]

After $2 \times 10^{6}$ cycles to failure, a change of crack initiation mechanism could be detected. Furthermore, a increase of scatter could be detected over several orders of magnitude. In Fig. 5 several specimens were investigated by SEM to identify the type of defect.

In Fig. 6 (marked in Fig. 5 with *) a representative fracture surface is displayed. Almost centred an inclusion could be found, which showed subsurface crack initiation. Mainly internal inclusions showed cracks emanating from the subsurface region (Fig. 6), primary $\mathrm{Al}_{2} \mathrm{O}_{3}$ oxides (and their complex chemical combinations including $\mathrm{MgO}$, etc.). 


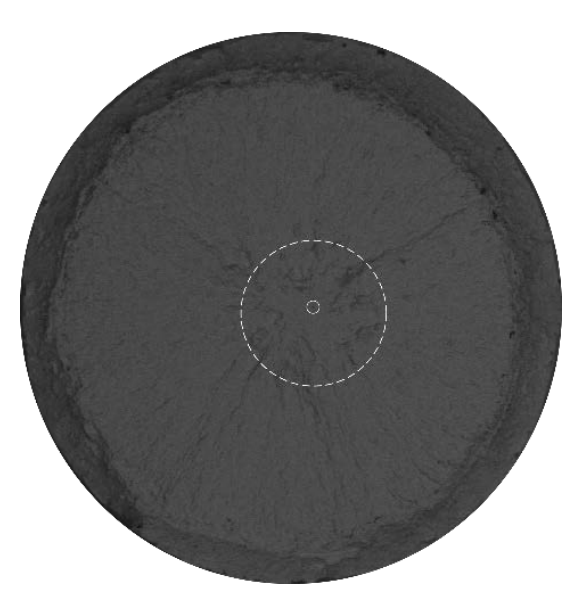

Fig. 6. SEM examinations revealed fish-eye fractures in $\mathrm{D}_{2.5}$ (picture) and $\mathrm{D}_{7.5}$ specimens, which showed $\mathrm{Al}_{2} \mathrm{O}_{3}$ inclusions without exception. Fracture surface presented at $2.25 \times 10^{8}$ cycles to failure.

Selected $D_{7.5}$ specimens $(30 \mathrm{~Hz})$ showed failures just after $10^{7}$ cycles, which were not taken into account for presented fatigue data up to $10^{7}$ cycles to failure. Therefore further investigations at $928 \pm 8 \mathrm{~Hz}$ were carried out.

Fracture surfaces, above $10^{8}$ cycles to failure, revealed FGA formations at a higher magnification (investigations in [19]). No FGA was found at lower lifetimes. A fatigue limit was examined to be nearly within the theoretical (extrapolated) fatigue limit of $\mathrm{D}_{7.5}$ results.

\subsection{Lifetime prediction}

Data presented in Fig. 4 was implemented $\left(D_{7.5}\right)$ into FEMFAT to ensure specimen lifetime calculations for $\mathrm{D}_{2.5}$ specimens.

An identical dataset was implemented into fe-safe for comparing simulations. As mentioned fe-safe is not applying gradient based approaches. Analyses were carried out under consideration of the v.Mises criterion.

In Fig. 7 the FEMFAT modification is displayed regarding the modified slope $\mathrm{k}_{\chi}$, cycles to the turn off point $\mathrm{N}_{\mathrm{D}, \chi^{\prime}}$ and the fatigue limit $\sigma_{\mathrm{D}, \chi^{\prime}}$. Due to the a relative stress gradient $\chi^{\prime}=0.1804$ at the surface of the specimen the modification, especially regarding the fatigue limit, was low.

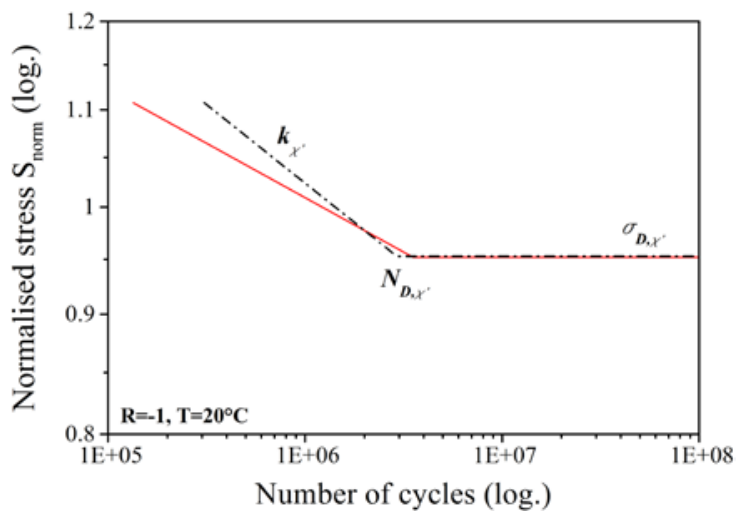

Fig. 7. Modification of $\mathrm{S} / \mathrm{N}$ parameters according to FEMFAT 5.3. The relative stress gradient $\chi^{\prime}=0.1804$ was applied.

In Fig. 8 results of the lifetime calculation are displayed. The solid line represents the transition from a conservative (test life $>$ simulation life) to a nonconservative (test life $<$ simulation life) regime. The dashed line describes a scatter of 3 compared to the referenced data $\left(D_{7.5}\right)$.

Due to the gradient approach FEMFAT results show a better result, almost within a scatter of 3 . Fesafe calculations showed a more conservative result as there is no modification of the initial fatigue data.

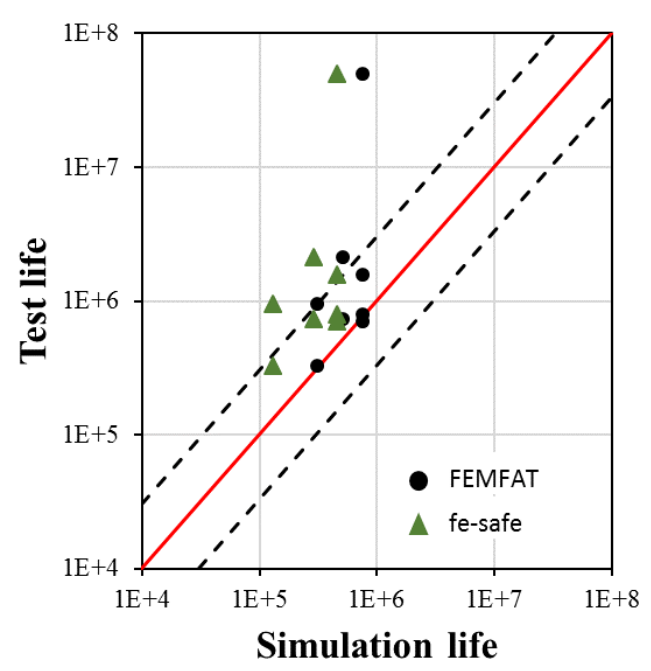

Fig. 8. Lifetime calculation results for three different load levels $\mathrm{S}_{\text {norm }}=1.1,1.07$ and 1.04 .

Simulations were carried out at different load levels $\mathrm{S}_{\text {norm }}=1.1,1.07$ and 1.04. From a load level of $\mathrm{S}_{\text {norm }}=1.04$ the scatter increased due to internal crack initiation. Lower load levels showed a very large deviation of results and therefore no calculations were presented.

\section{Discussion}

Here the results are discussed regarding different aspects of presented investigations. It was shown how data was applied regarding smaller specimen sizes. 
Usually specimen geometries are smaller compared to actual component geometries. Regarding presented results a larger volume shows a decrease of fatigue strength compared to specimen fatigue tests. Presented investigations represent a preliminary study concerning the applicability of standard fatigue data to smaller volumes.

$\mathrm{D}_{7.5}$ specimen fatigue data was used for many applications, always extrapolating the fatigue strength to larger component volumes. Therefore reduction factors were defined such as stress gradient and surface roughness.

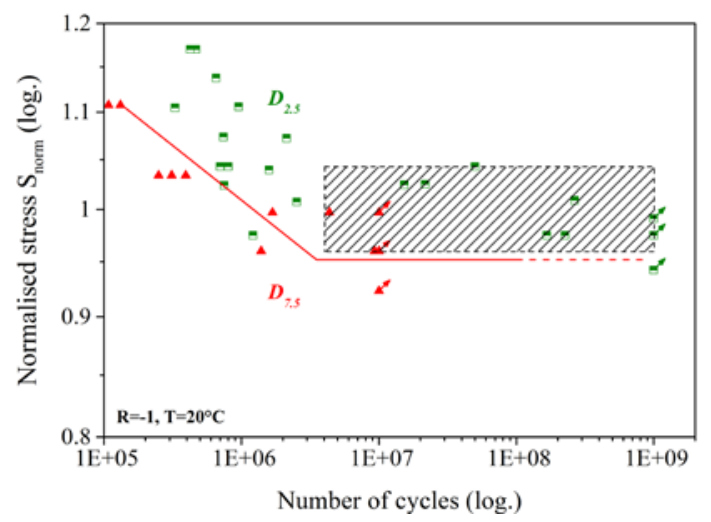

Fig. 9. Fatigue results of $D_{7.5}$ and $D_{2.5}$ tests and comparison of fatigue data. The critical area is displayed as shaded rectangle.

In Fig. 9 a summary is shown comparing two fatigue test results. Conventionally $\mathrm{D}_{7.5}$ results (statisctical evaluation, fatigue limit) are extrapolated up to higher cycles. This approach is going to fail applied on $\mathrm{D}_{2.5}$ results, especially taking into account fatigue tests failed at $>10^{8}$ cycles. Some Materials exhibit a traditional fatigue limit evaluated at $10^{7}$ cycles to failure. The presented material configuration, and of course various other materials, do not show a constant amplitude limit. This issue is still not considered within software tools, whereas FEMFAT offers damage calculation according to Miner's cumulative damage models.

The VHCF regime, which is defined to be from $10^{7}$ to $10^{9}$ cycles to failure, was analysed by additional tests. The shaded area in Fig. 9 represents the most critical area in terms of lifetime calculation. Up to now no ready-to-use approach was presented regarding characteristic values for a further implementation. Well-known defect based fatigue strength models were presented by Murakami [25,26] amongst others. Miner's rule lacks of statistical information, which is another issue in the actual investigation.

fe-safe provides the possibility of a more detailed application of S/N data. Every S/N relationship can be established and especially the application in the VHCF regime could be interesting as a multi kinked $\mathrm{S} / \mathrm{N}$ curve could be realised. Therefore more detailed data is needed in the VHCF regime to evaluate the material's fatigue behavior beyond $10^{7}$ cycles.

In the future additional tests will be carried out to improve fatigue data up to $10^{9}$ cycles to failure. Future applications are going to reach higher lifetimes as a result of lightweight design and a higher power density. Further studies will concentrate on the different possibilities of fatigue data implementation and how this could be improved.

\section{Conclusion}

In this work, fatigue tests up tp $10^{9}$ cycles to failure were presented under the consideration of decreasing specimen geometries. Additional to that the material behavior and subsurface crack initiation were presented. The fatigue data was implemented into common software tools and calculation results were summarised and discussed. Concluding remarks can be recorded as follows:

- Fatigue tests were presented taking into account the material properties and the change of the crack initiation mechanism.

- Tests showed the difference between classic fatigue data at $10^{7}$ cycles to failure compared to data up to $10^{9}$ cycles to failure.

- SEM analyses showed $\mathrm{Al}_{2} \mathrm{O}_{3}$ inclusions to be the main type of inclusion found in this material.

- Damage approaches were presented comparing two different software tools.

- Lifetime calculations showed the issues of conventional approaches and that the increase of scatter is not covered at all.

\section{Acknowledgements}

The authors would like to acknowledge the financial support of the "COMET - Competence Centres for Excellent Technologies Programme" of the Austrian Federal Ministry for Transport, Innovation and Technology (BMVIT), the Austrian Federal Ministry of Science, Research and Economy (BMWFW) and the Provinces of Styria, Tyrol and Vienna for the K1-Centre LEC EvoLET. The COMET Programme is managed by the Austrian Research Promotion Agency (FFG).

\section{References}

[1] Bathias, Fatigue \& Fracture of Engineering Materials \& Structures 7 ,559-565 (1999).

[2] C. Bathias ,163-171 (2000).

[3] Y. Murakami, International Journal of Fatigue 9 ,661-667 (1998).

[4] Y. Murakami, T. Nomoto, T. Ueda, Fatigue \& Fracture of Engineering Materials \& Structures 7 ,581-590 (1999).

[5] H. Mughrabi, Fat Frac Eng Mat Struct 8-9 ,755764 (2002).

[6] H. Mughrabi, International Journal of Fatigue ,28 (2013).

[7] Miller, O’donnell, Fatigue Fract Engng Mater Struct 7 ,545-557 (1999). 
[8] I. Milošević, C. Garb, G. Winter, F. Grün, M. Kober, Procedia Structural Integrity ,327-334 (2017).

[9] R. Schnitzer, Proceedings of the 8th International Tooling Conference Vol. I ,491-503 (2009).

[10] R. Schnitzer, R. Radis, M. Nöhrer, M. Schober, R. Hochfellner, S. Zinner, E. Povoden-Karadeniz, E. Kozeschnik, H. Leitner, Materials Chemistry and Physics 1 ,138-145 (2010).

[11] R. Schnitzer, S. Zinner, H. Leitner, Scripta Materialia 5 ,286-289 (2010).

[12] J. Wang, H. Zou, C. Li, S.-y. Qiu, B.-1. Shen, Materials Characterization 4-5 ,274-280 (2006).

[13] J. Wang, H. Zou, X.-y. Wu, S.-y. Qiu, B.-1. Shen, Nuclear Power Engineering Vol. 26. No.3 ,254258 (2005).

[14] J.-H. Wu, C.-K. Lin, Materials Science and Engineering: A 1-2 ,291-298 (2005).

[15] J.-H. Wu, C.-K. Lin, Metall and Mat Trans A 6 ,1715-1724 (2002).

[16] B.M. Schönbauer, K. Yanase, M. Endo, International Journal of Fatigue ,205-216 (2016).

[17] H. Mughrabi, R. Wang, K. Differt, U. Essmann, ASTM International ,5-41 (1983).

[18] I. Milošević, P. Renhart, G. Winter, F. Grün, M. Kober, International Journal of Fatigue ,150-157 (2017).

[19] I. Milošević, P. Renhart, G. Winter, F. Grün, M. Kober (2018).

[20] I. Milošević, G. Winter, F. Grün, M. Kober, Frattura e Integrita Strutturale 42 (2017).

[21] I. Milošević, G. Winter, F. Grün, M. Kober, Procedia Engineering ,61-68 (2016).

[22] W. Eichlseder, Rechnerische Lebensdaueranalyse von Nutzfahrzeugkomponenten mit der Finite Elemente Methode, 1989.

[23] ASTM International, Standard Practice for Statistical Analysis of Linear or Linearized Stress-Life $(S-N)$ and Strain-Life $(\varepsilon-N)$ Fatigue Data, ASTM International, West Conshohocken, PA, 1998 (accessed on July 10, 2017).

[24] D. Dengel, Mat.-wiss. u. Werkstofftech. 8 ,253261 (1975).

[25] Y. Murakami, T. Nomoto, T. Ueda, Fat Frac Eng Mat Struct (Fatigue Fracture of Engineering Materials and Structures) 11,893-902 (2000).

[26] Y. Murakami, Fatigue 90 ,377-382 (1990). 